\title{
A CORTINA RASGADA: O CINEMA De Alfred HitchCock e A TEORIa dA IMAGEM EM SigMUND FREUD
}

\author{
THORN RAPE: THE CINEMA OF ALFRED HITCHCOCK \\ AND THE THEORY OF IMAGE IN SIGMUND FREUD \\ LA CORTINA RASGADA: EL CINE DE ALFRED HITCHCOCK \\ Y LA TEORÍA DE LA IMAGEN DE SIGMUND FREUD \\ Karla Patricia Holanda Martins* \\ Débora Passos de Oliveira** \\ Maria Celina Lima Peixoto***
}

\section{ResUMo}

O presente trabalho parte da premissa de que o suspense, tal como representado na obra do cineasta Alfred Hichtcock, figurabiliza um modo de funcionamento do aparelho psíquico análogo àquele demarcado no modelo freudiano. Ao articular o cinema de Hitchcock à dimensão da imagem em Freud propóe evidenciar determinada autonomia do registro imagético na teoria freudiana. Se a práxis psicanalítica tem na linguagem seu aporte fundamental, não podemos nos esquecer de que a imagem produz também seus efeitos psíquicos, sobretudo no instante em que excede o registro da linguagem. Nesse sentido, nos apoiamos nas articulaçóes de Hitchcock para desvelar as formas de representação relativas à imagem que se apresentam na teoria psicanalítica. À vista disto, desloca-se o ponto de vista de usar a psicanálise como instrumento teórico para pensar o cinema em direção a uma perspectiva em que a imagem fílmica pode oferecer visibilidade aos processos psíquicos conhecidos apenas pelos seus efeitos. Desse modo, é a

* Universidade Federal do Ceará, Fortaleza, CE, Brasil; Universidade de Fortaleza, Fortaleza, CE, Brasil; ANPEPP - Associação Nacional de Pesquisa e Pós-Graduação em Psicologia, Brasil.

** Universidade de Fortaleza, Fortaleza, CE, Brasil.

*** Universidade de Fortaleza, Fortaleza, CE, Brasil. 
construção cinematográfica que nos auxilia a vislumbrar as formações do inconsciente demarcadas no texto freudiano.

Palavras-chave: imagem; linguagem; Hitchcock; Freud.

\section{Abstract}

This present work assumes that suspense, as represented in the work of filmmaker Alfred Hichtcock, produces images of a way the psychic apparatus works analogous to the one marked by the Freudian model. By articulating Hitchcock films to the dimension of image in Freud, we seize to highlight a certain autonomy of the imagetic registry in Freudian theory. If psychoanalytic praxis has in its praxis its fundamental contribution, we cannot forget that images also produce psychic effects, especially in circumstances where it exceeds the record of language. Therefore, we do not wish to use psychoanalysis as a theoretical tool for thinking the film but aim at a perspective where the filmic image can offer visibility to psychic processes known only by its effects. Thus, the cinematic construction helps us to glimpse the unconscious formations present in Freudian texts.

Keywords: image; language; Hitchcock; Freud.

\section{RESUMEN}

Este trabajo parte de la premisa de que el suspense, como se representa en la obra del cineasta Alfred Hichtcock, figurabiliza un modo de funcionamiento del aparato psíquico análogo al demarcado en el modelo freudiano. Al articular el cine de Hitchcock con la dimensión de la imagen en Freud, se propone evidenciar certa autonomía del registro de imágenes en la teoría freudiana. Si la praxis psicoanalítica tiene en el lenguaje su contribución fundamental, no podemos olvidar que la imagen también produce sus efectos psíquicos, especialmente el instante en el que supera el registro de la lengua. En este sentido, apoyamos las articulaciones de Hitchcock para revelar las formas de representación, relativas a la imagen, que está presente en la teoría psicoanalítica. En vista de esto, se mueve el punto de vista de utilizar el psicoanálisis como herramienta teórica para pensar el cine em dirección a una perspectiva donde la imagen filmada puede proporcionar visibilidad a los procesos psíquicos conocidos sólo por sus efectos. Por lo tanto, es la construcción cinematográfica que nos ayuda a vislumbrar las formaciones del inconsciente demarcadas en el texto freudiano.

Palabras clave: imagen; lenguaje; Hitchcock; Freud. 
No âmbito dos trabalhos escritos sobre Hitchcock este artigo propóe uma articulação entre seu gênero de suspense e a psicanálise, a partir, primordialmente, das suas declaraçóes, estabelecendo-se ainda relaçóes com o que dizem os críticos e psicanalistas estudiosos da sua obra. Para a realização de tal tarefa, parte-se da premissa de que o suspense, tal como representado em sua obra, figurabiliza a temporalidade do a posteriori e, simultaneamente, aproxima, através da sua concepção de imagem, o campo das representaçóes do domínio pulsional. Desloca-se o ponto de vista de usar a psicanálise como instrumento teórico para pensar o cinema em direção a uma perspectiva em que o cinema pode oferecer visibilidade aos processos psíquicos conhecidos apenas pelos seus efeitos. Desse modo, é a construção cinematográfica que nos auxilia a vislumbrar as formaçóes do inconsciente, demarcadas no texto freudiano.

\section{Sonhos... sonhos são?}

Jane Sloan (1993) dedica um capítulo de sua obra Alfred Hitchcock: a guide to references and resourses à análise dos trabalhos escritos sobre o cineasta e sua obra até aquela ocasião. Entre estes, muitos deles foram desenvolvidos a partir de uma abordagem psicanalítica. Dos cineastas que trabalharam na América dos anos 40 aos anos 70 Hitchcock é um dos mais populares. Tendo conhecimento de que o sucesso era garantia para se manter independente das imposiçóes dos grandes estúdios, esteve sempre atento aos gostos de seu público, sem abrir mão de uma marca autoral.

Já consagrado pela crítica, Hitchcock chega a Hollywood em 1940, convidado pelo produtor David O. Selznick - que havia acabado de emplacar grande sucesso com o filme E o vento levou - para dirigir Rebecca. Desde então, habilidosamente, o cineasta joga com dois níveis da narrativa cinematográfica: num nível, não decepciona o espectador que espera reconhecer o relato; em outro, impóe, através das imagens e não dos diálogos, um plano onde o espectador e os protagonistas escorregam cada vez que acreditam ter alcançado o sentido: "a ficção é aquilo que escapa à narrativa” (Veillon, 1993, p. 106). É precisamente aqui, no plano da ficção, tomada como análoga da estruturação psíquica, que o cinema de Hitchcock demonstra suas afinidades com a psicanálise.

Mesmo quando realizou filmes com enredos que, numa certa dimensão, eram traduçóes pedagógicas de teses psicanalíticas (dos quais Quando fala o coração de 1945 e Marnie, confissóes de uma ladra de 1964 são os exemplos mais evidentes), Hitchcock conseguia expressar um efeito que colocava espectador e 
protagonista numa relação com a verdade que só podia ser semidita; o herói hitchcockiano é, afirma Veillon (1993, p. 108), "um equilibrista em trânsito para o desconhecido". Se, de um lado, ele satisfazia o interesse do espectador por apresentar a visão de mundo a partir do que conhecia da psicanálise difundida nos Estados Unidos, de outro o inquietava quanto ao sentido que lhe fora oferecido. Veillon (1993) aponta para o fato de o cineasta ter conseguido ir além dos conteúdos impostos pelos produtores, mesmo com relação à psicanálise. Ao comentar com Truffaut a respeito do filme Quando fala o coração, Hitchcock (Truffaut, 1967/1986, p. 98) define: "é uma vez mais uma história de caça ao homem, mas aqui envolta em pseudopsicanálise". Ao mesmo tempo, revela que o que queria deste filme era "apenas rodar o primeiro filme de psicanálise" (Truffaut, 1967/1986, p. 97). Estas observaçóes demonstram, de maneira paradoxal, o seu interesse pela temática freudiana e a consciência das diferenças entre a experiência psicanalítica e o lugar da psicanálise na cultura. Mas então, o que efetivamente a psicanálise poderia lhe oferecer?

Hitchcock confessou a Truffaut sua pretensão de realizar filmes "sem rombos, nem manchas" (Truffaut, 1967/1986, p. 15). Referia-se à sua tentativa de aproximar as imagens fílmicas das imagens do mundo de vigília. Sua atitude repousa em uma negação do entendimento do filme como sonho e da imagem como o equivalente da representação. O princípio do suspense supóe esta espécie de estado de vigília do espectador. É esta a sua inversão mais genial: reproduzir o estado de atenção e expectativa do sujeito no momento em que se encontra diante de algo (a imagem) que é um misto de virtualidade e realidade, ou ainda, que comporta a representação e seu negativo. Desta forma, ele forja uma situação, uma outra cena, em que o sujeito está frente a uma realidade que ao mesmo tempo que se impóe à percepção não é totalmente apreensível; ou seja, introduz-se aí a função pulsátil do olhar. Slavoj Zizek (2013) oferece uma definição exemplar dessa função paradoxal do olhar. Em sua última obra - Menos que nada: Hegel e a sombra do materialismo dialético - ele destaca a recorrência insistente dessa temática nos clássicos de Hitchcock (Psicose; Os pássaros): sempre que a heroína (Lilah ou Melaine) se aproxima de uma casa misteriosa ou vazia, somos surpreendidos, mediante um salto de perspectiva, pelo ponto de vista da própria casa que reenvia este olhar para o sujeito. Para Zizek (2013), esse olhar da casa não deve ser jamais interpretado como um tipo de olhar subjetivado (alguém que observa do seu interior), mas em última instância como um olhar radicalmente vazio, uma espécie de olhar a priori não apreendido numa realidade dada: "a heroína 'não pode ver tudo', há um ponto cego naquilo que ela olha, e o objeto retorna seu olhar a partir desse ponto cego" (Zizek, 2013, p. 380). É por 
isso que afirmamos, sem hesitar, que a psicanálise tem muito a aprender com (ou a perguntar a) Hitchcock.

Em 1967, ao longo da extensa entrevista concedida a Truffaut, conversa que durou três dias, Hitchcock analisou seus filmes, esclareceu que o suspense, tal como ele operava, possuía regras e leis próprias. Em cada uma das declaraçóes reforça a ideia de que tudo se resume ao jogo com a duração, com a paciência e com a espera (Truffaut, 1967/1986, p. 46). A duraçáo está necessariamente vinculada a um conhecimento que já foi antecipado ao espectador e com o qual este constrói uma expectativa. Por este motivo, definir o suspense implica, para Hitchcock, estabelecer um divisor de águas com a surpresa. Nas suas palavras:

Suponhamos que temos um grupo de homens sentados em volta de uma grande mesa redonda, coberta por um feltro verde. Eles estão, como você deve ter concluído, jogando pôquer. Então, uma bomba explode no meio deles. Isto é susto (ou surpresa). Agora, suponhamos que nós temos os mesmos homens, na mesma mesa jogando o mesmíssimo jogo. Mas desta vez, antes do jogo começar, nós focalizamos embaixo da mesa e vemos uma bomba relógio, e seus ponteiros funcionando. Agora nós voltamos a câmera para a mesa e as cartas já foram distribuídas. O relógio continua a fazer aquele barulho tão peculiar... Um dos jogadores descarta rapidamente suas cartas, levanta-se subitamente e deixa a sala. Ele sabe algo que os outros não sabem. O tiquetaque do relógio fica mais alto e o espectador sabe disto também. Isto é suspense (Hitchcock, citado por Truffaut, 1967/1986, p. 50).

Eis aí anunciada a regra fundamental: no suspense, há um nível de certeza antecipada que coloca o espectador numa posição de espera. No filme Festim diabólico (1948), por exemplo, os espectadores dividem com os assassinos o conhecimento de que há um cadáver escondido na sala onde um jantar será servido. De 19:30h às 21:15h (tempo real da ação e de duração do filme), a investigação é acompanhada pelos espectadores. No entanto, diante da informação, a tensão de ambos (protagonista e público) aumenta. Esse jogo transforma os 105 minutos "reais" em tempo de espera; trata-se do tempo cronológico e, principalmente, da sua subjetivação. Neste sentido, afirma Aumont (1993, p. 107): "o sentimento do tempo não decorre, portanto, da duração objetiva dos fenômenos, mas sim de mudanças em nossa sensação do tempo, que resultam do processo de interpretação que operamos". 
É interessante observar como este mesmo aspecto - o desenvolvimento da ação em tempo cronológico e as longas tomadas que dão ao espectador a sensação de continuidade - provocou uma série de questionamentos no próprio diretor, inclusive o de que este experimento o havia distanciado do cinema e por isso deveria ser esquecido. Sua insatisfação com o filme talvez repousasse sobre a regra enunciada por ele, segundo a qual, "o tempo no cinema não deveria nunca ter relaçóes com o tempo real" (Hitchcock, citado por Truffaut, 1967/1986, p. 46). No entanto, a avaliação do cineasta não coincide com alguns dos críticos de sua obra. Thomas M. Bauso (1991) desenvolve um ponto de vista oposto ao do cineasta: vê em Festim diabólico a libertação de Hitchcock da sua necessidade de exercer o controle sobre o tempo real, fato este que o libera para o exercício estilístico da sua câmera, agora flutuante e livre para fazer derivar múltiplas relaçóes entre os signos. O que continua em questão é que o controle exercido é de ordem subjetiva. Embora as açôes se desenrolem em tempo real, perdura um jogo com um outro tempo, o de espera.

Outras marcas fundamentais derivadas da regra que determina um uso econômico da temporalidade são a clareza e a simplificação. Se por um lado o cineasta as promove junto à informação e ao controle do tempo, pode-se dizer, por outro lado, que o espectador submetido a essas açóes possui, pelo menos em determinado nível, um registro dos elementos que constituem a pergunta: e agora, quando vai acontecer?

O suspense é construído ainda a partir de outra regra: o cotidiano possui um potencial de anormalidade. No seu livro Do assassinato como uma das Belas Artes (1993), o escritor inglês Thomas De Quincey defende a tese de que um dos princípios estéticos fundamentais para que o assassinato tenha valor de arte é que as escolhas - vítima, local, momento - repousem sobre a regra geral da suposta normalidade. Para um belo crime não é fundamental um ambiente lúgubre: este deve ser cometido à luz do dia. A vítima deve gozar de boa saúde, ser um anônimo e não poder jamais contemplar a possibilidade de assassinar alguém. Tais regras são, na maioria das vezes, cumpridas à risca por Hitchcock. O suspense é atingido a partir do clichê, do banal, do familiar. A observação de Truffaut (1967/1986) quanto ao fato de este princípio ser tanto plástico quanto intelectual é valiosa, posto que nos chama a atenção para uma lógica desta construção: a que supóe a existência de uma potência de instabilidade no cotidiano. É um princípio estético, mas é, sobretudo, um princípio lógico; e, como tal, absolutamente arbitrário.

Quando Hitchcock (Truffaut, 1967/1986), ao comentar o seu filme Os pássaros, diz que é preciso filmar flores que comem homens mais do que perfumes que envenenam, ele opta por uma lógica que não é a do senso comum. 
Admite que se inspirou em fatos reais - corvos atacando cordeiros - para filmar a sequência em que os pássaros arrancam os olhos de um homem. $\mathrm{O}$ traço por ele reproduzido na ficção é o afeto de horror que ambas as situaçóes causam. Com esta estrutura, rompe com a tradição cinematográfica (e literária) que associa o fantástico aos fenômenos sobrenaturais e/ou irreais: o suspense hitchcockiano é efeito de uma percepção de irrealidade no que há de mais real.

Quanto à sustentação de um nível de apetência e curiosidade do espectador, Hitchcock diferencia pelo menos dois planos: um, em que apresenta uma visibilidade que pode ser compartilhada pelo público; e outro, no qual convoca o espectador para o entendimento de um nível subjetivo ou psicológico da trama. Ilustra suas estratégias com as apariçóes dos pássaros em planos secundários, sustentando o nível de curiosidade do espectador num limiar que não comprometia a atenção quanto ao conteúdo dramático manifesto. Desta forma, conduz o espectador do realismo ao simbolismo sem jamais abandonar as remissóes à realidade. Trías (1986) identifica a genialidade do cineasta nesta capacidade em manter sempre um plano superficial, aparente, no qual se desenvolve a trama e um complexo mundo de referências simbólicas, todas, sem dúvida, possuindo um rendimento dramático na ação.

Uma tal estrutura narrativa leva Bonitzer (1982) à afirmação de que a função do crime é produzir na tela uma mancha, um rasgo para onde o olhar do espectador se precipita; até este ponto da narração tudo parecia natural e inocente. A partir desta mancha, os signos são pervertidos e se instaura um estado de instabilidade. $\mathrm{O}$ ponto de partida são emblemas do convencional e familiar. Todavia, desde o início do filme, o público jamais adere totalmente à ingenuidade aparente da imagem. Se existe por parte do narrador a produçáo de duplos níveis narrativos, no que diz respeito à crença do espectador algo de semelhante se desenvolve. Com a finalidade de estabelecer esses diferentes níveis narrativos nos filmes, levando ideias e emoções ao paroxismo, o diretor opera um truque na maneira de narrar suas histórias: para cada avanço da trama faz corresponder um rearranjo no sentido.

\section{A imagem em Hitchcock: o ponto de suspensáo do espectador}

Gilles Deleuze (1990) assinala o fato de que, muito cedo, o cinema europeu se defrontou com um conjunto de fenômenos - amnésia, hipnose, alucinação, delírio, e, sobretudo, pesadelo e sonho - inaugurando uma narrativa em 
torno do invisível. A partir destas consideraçōes, o filósofo francês diferencia dois tipos de imagens produzidas pelo cinema, quais sejam: a imagem-movimento e a imagem-tempo, respectivamente. Se na primeira temos imagens em que os personagens exibem respostas imediatas a determinadas sensaçóes, cada sensação correspondendo a uma resposta motora, no segundo caso temos situaçóes nas quais os personagens, marcados pelo conflito, se mostram indecisos ou impotentes frente à escolha da ação. "Os protagonistas passam de actantes a videntes, tornando-se uma espécie de espectador" (Deleuze, 1990, p. 11). Em outras palavras, ao invés da percepção-ação motora tem-se a percepção-pensamento. Esta reversão (de actante a vidente) é fundamental na definição do lugar do espectador: agora ele se encontra incluído no filme. Deleuze (1990) aponta Hitchcock como o cineasta que inaugura esta reversão. Desta forma, a trama das imagens se esboça mais numa relação com o tempo, ao qual o movimento se subordina. É claro que a imagem-movimento não desaparece, mas passa a existir como "a primeira dimensão de uma imagem que não para de crescer em dimensões" (Deleuze, 1990, p. 33). Consequentemente, neste tipo de filme a modalidade temporal constrói uma determinada posição subjetiva em que protagonistas e espectadores tentam, via interpretação, alcançar uma percepção que está sempre adiante. Desse modo, é como se eles estivessem sempre atrasados para estabelecer ligaçóes. Estas conjunções forjam espectadores e protagonistas atentos aos indícios e aos pequenos detalhes.

Na construção deste lugar subjetivo, a utilização da câmera é um recurso de importância fundamental. Seus enquadramentos passam a captar as relaçóes mentais, não se restringindo a descrever os objetos, a reproduzi-los segundo uma funcionalidade já estabelecida. Entretanto, não se trata de traçar distinções entre o subjetivo e o objetivo. É, ao contrário, a sua indiscernibilidade que vai dotar a câmera de uma consciência.

Se no cinema de Hitchcock o espectador adquire uma posição subjetiva no desenrolar da trama, este fato é devido, sobretudo, à forma com que o diretor compartilha, com suas testemunhas, elementos essenciais ao enredo. Estas pistas são dadas a partir do jogo de imagens, recurso decisivo na constituição do suspense.

\section{$O$ inconsciente estruturado enquanto imagem}

Freud (1895/2007), já no seu "Projeto para uma psicologia científica", demonstra que há algo na imagem que se constitui como ponto de fuga, do qual 
apreendemos apenas os efeitos, indicando que não há correspondência imprescindível entre a imagem e a palavra. Deste modo, o cinema que acolhe o inconsciente coloca em cena o ponto de fuga da imagem, produzindo efeitos de sentido que não precisam estar necessariamente articulados, ponto a ponto, nos diálogos. Quando Freud (1895/2007) nos fala da decomposição do complexo perceptivo em uma parte assimilável pelo pensamento e outra resistente à sua compreensão, o que está fora se recusa ao pensamento e à palavra, mas náo à imagem. Aqui se constroem os primeiros passos de uma teoria freudiana sobre os sonhos e as fantasias. Ao tornar signo o invisível, o cinema toca em uma realidade sobre a qual a psicanálise teoriza. No "Projeto para uma psicologia científica" (Freud, 1895/2007), examinamos que a incompatibilidade das características do psiquismo de se manter receptivo e, ao mesmo tempo, conservar a percepção nos traços mnêmicos leva Freud a estabelecer diferença entre uma representação e uma percepção. É no intervalo entre a percepção e a memória que a fantasia toma lugar. Mais precisamente, é por haver um espaçamento entre estas duas funçóes que o conceito de memória encontra-se, em Freud, mais associado à dimensão criativa que ao simples arquivamento de um acontecimento. Desse modo, a relação entre a memória e a fantasia póe em evidência o lembrar criativo como uma característica essencial do trabalho mnêmico.

Se no "Projeto para uma psicologia científica" Freud (1895/2007) apresenta uma noção de representabilidade a partir da linguagem neurofisiológica, na "Carta 52" (Freud, 1896/2007), texto posterior, a exposição desta ideia não se limita unicamente ao uso de termos biológicos. Embora a apenas um ano de distância daquele texto, a Carta opta por uma linguagem antes própria à psicologia que à neurologia; vemos ali surgir termos como: tradução, transcrição, signo etc., que são, aliás, elementos próprios a isto que se compreende comumente por registro escrito. $\mathrm{O}$ aparelho psíquico - inscrito nos traços mnêmicos - é gerado, segundo Freud, por um processo de estratificação sucessiva. O primeiro a ser ressaltado é que este processo estabelece camadas que são feitas por etapas e que produzem a divisão dos processos representacionais em subsistemas. A multiplicidade da memória estaria garantida pelo registro em diferentes tipos de signos. Além disso, as diversas transcrições da memória estão relacionadas aos seus respectivos portadores neuronais - de uma maneira não necessariamente tópica - assim como ao nexo associativo a que, de tempos em tempos, a memória é submetida.

O primeiro sistema, por assim dizer, se refere ao sistema perceptivo que é formado por neurônios da percepção, aos quais a consciência se liga, mas que não conservam, em si, nenhum traço do que aconteceu. Podemos observar, desse modo, a incompatibilidade evidenciada por ele entre percepção e representação. 
Freud coloca a percepção (mais precisamente, o órgão responsável pela recepção dos estímulos sensoriais) e a consciência em polos opostos, porém intimamente associados entre si. Entre eles estariam situados os registros da memória. A estimulação externa que alcança o sistema perceptivo apenas se torna consciente após atravessar todos os sistemas da memória. Desse modo, o que se apresenta à consciência é o produto de uma série de retranscrições da excitação externa; o que faz com que a percepção da realidade seja representada apenas indiretamente. Freud começa a delinear, pois, a especificidade de sua noção de realidade, que não se reduz à realidade material, mas que, no entanto, não a destitui completamente.

Os três registros subsequentes ao sistema perceptivo se relacionam aos traços mnêmicos, os quais são representados como $P s$ (signo de percepção), Icc (inconsciência) e Prcc (pré-consciência). Segundo Freud, cada sistema mnêmico corresponde a uma forma específica de representar a percepção de acordo com a respectiva etapa do desenvolvimento psíquico, bem como a uma etapa do curso excitatório que leva da percepção à consciência. A memória estaria subdividida, deste modo, conforme períodos de tempo. O material psíquico, ao passar de uma etapa a outra, seria submetido a um processo de tradução (Übersetzung). Contudo, é imprescindível ressaltarmos que o traço mnêmico não é em si pensamento: para que este processo ocorra é necessária uma articulação entre várias representaçôes. Logo, não podemos afirmar que o pensamento se confunde com a associação de impressóes inconscientes. A imagem possui uma determinada autonomia frente aos processos de pensamento

Da percepção ao signo de percepção, tem lugar a primeira inscrição (Niederschrift), com base na qual se seguiriam as subsequentes transcrições (Umschrift). É interessante observarmos que de uma imagem perceptiva consciente $(P)$ se originam inscrições e transcrições não conscientes. Os signos de percepção $\left(P_{S}\right)$ estariam articulados conforme uma associação por simultaneidade, já o segundo registro $(I c c)$, correspondente a representaçóes de conceitos inconscientes, estaria organizado em conformidade com outros nexos, talvez por causalidade. O sistema pré-consciente ( $P r c c$ ) está ligado à representação-palavra; desde esse registro, os traços mnêmicos se tornariam conscientes obedecendo, pois, algumas regras. Os traços mnêmicos definem os signos de acordo com as suas articulações: por simultaneidade, causalidade e em relação à representação-palavra dos pensamentos pré-conscientes. Desse modo, os traços mnêmicos são como diferentes formas de escrita: em figuras e imagens (os inconscientes) ou associadas a palavras (os pré-conscientes). À vista disto, existiria um tipo de escrita figural e uma outra linguística. 
É nesse momento que a análise empreendida por Lacan no seminário sobre a ética nos presta auxílio. Lacan (1959-1960/1992) retoma uma crítica realizada, sobretudo por Jean Laplanche, às suas formulaçóes acerca da estruturação do inconsciente como um campo de linguagem. O debate centrava-se na distinção feita por Freud, no artigo $O$ inconsciente, entre representação-coisa (Sachvorstellung) e representação-palavra (Wortvorstellung). Nesse artigo, Freud atribui as representaçóes-coisa ao inconsciente e as representaçóes-palavra ao sistema pré-consciente. O que Lacan acentua é que a distinção entre palavra e coisa diz respeito a uma tradição da filosofia alemã com a qual Freud não compactuaria. Freud, de acordo com o psicanalista francês, anuncia, em contrapartida, uma inter-relação entre palavra e coisa, pois uma não existiria sem a outra, e um movimento de criaçấo das coisas através de sua articulação com as palavras. Assim, o inconsciente é conhecido - e criado - no momento em que é posto em palavras. Não existiria, assim, uma divisão radical entre o inconsciente e o pré-consciente.

De todo modo, haveria, por conseguinte, uma outra forma de inscrição que comporta uma dimensão semântica, ainda que de forma elementar. É o que Freud denomina na "Interpretação dos sonhos" (1900/2007) como condiçáo de figurabilidade, associada, aliás, à pintura e às artes plásticas que se contrapóem, por sua vez, à poesia, uma vez que esta arte pode servir-se da fala. Em certa medida, as elaborações contidas na "Interpretação" são, em geral, uma forma de ilustrar a capacidade do inconsciente de representar por imagens. De modo que haveria um tipo de recordação, relacionada a estas inscriçóes primárias, que difere radicalmente de uma recordação já associada ao registro verbal. Em conformidade a isto, torna-se mais evidente a relação traçada por Freud entre recordação e alucinação. Segundo ele, as vivências infantis mais arcaicas, quando tornadas rememoraçóes conscientes, são lembradas de forma alucinatória (1900/2007, p. 539). O caráter alucinatório está associado, desse modo, ao registro mnêmico que a evocação traz à tona.

Pensar a psicanálise a partir do cinema de Hitchcock nos possibilita evidenciar este caráter de figurabilidade do inconsciente. Desse modo, é mais uma vez à arte que recorremos.

\section{A realidade freudiana: uma memória em suspense}

Retomando as elaboraçóes sobre a percepção e o traço mnêmico, Freud afirma que todas as representações mentais (Vorstellungen) se originam da percepção, sendo, em última instância, a própria memória uma repetição desta última. Desse 
modo, a oposição clássica entre o subjetivo e o objetivo não se evidencia táo claramente assim. Mais precisamente, se as representaçóes são a princípio entendidas como repetiçóes da percepção, estas não se diferenciariam substancialmente do objeto ele mesmo, tal como se apresenta na realidade externa. No entanto, uma vez ocorrida esta distinção, isto se deve a fortiori à existência, já mencionada, de uma defasagem entre a percepção e a representação. Dito de outra forma, os traços de memória não possuem uma relação de identidade com o objeto percebido. $\mathrm{O}$ que marcaria, portanto, este desencontro? A resposta, segundo Freud, é a capacidade do psiquismo de reproduzir, presentificar o objeto a partir do seu próprio interior, ou seja, a partir da rememoração. Se utilizarmos o jogo de câmeras como uma metáfora da realidade psíquica, podemos demonstrar o caráter indiscernível entre a câmera que apreende a realidade e a realidade externa ela mesma. Estas duas dimensóes encontram-se, necessariamente, inseparáveis na construção da realidade psíquica.

O que está em questão é, por definição, uma determinada independência do psiquismo, do subjetivo, com relação à realidade. Segundo Freud (1925/2007, p. 255), “[...] o pensar possui a capacidade de novamente presentificar, através da reprodução na representação, algo que já foi uma vez percebido, para o qual não faz diferença que o objeto esteja no mundo externo". Pode-se dizer com precisão que tal aspecto do psiquismo é amplamente explorado por Freud desde seus primeiros textos. É, pois, devido a esta disposição que o psiquismo necessita sempre de signos de realidade para confirmar que o objeto está presente na realidade. Desse modo, segundo Freud (1925/2007), é necessário saber se aquilo que está disponível na forma de uma representação (Vorstellung) pode ser reencontrado na percepção (realidade).

Segundo Freud (1896/2007), a consciência é um efeito posterior ( $\mathrm{Na}$ chträglich) na ordem do tempo, provavelmente relacionada, conforme ele, à "reanimação alucinatória" das representaçóes-palavra. Este efeito de reanimação posterior é elaborado mais detidamente a partir de uma análise sobre a regressão onírica no capítulo VII da "Interpretação" (Freud, 1900/2007). Vejamos. No artigo de 1900, o psicanalista apresenta duas características fundamentais do sonhar, quais sejam: primeiro, o sonho é representado como uma situação presente, segundo, a formação onírica possui, no mais das vezes, a peculiaridade de ser vivenciada, ou seja, os traços mnêmicos são transformados em imagens sensíveis. Não estaríamos, desse modo, tão adormecidos quanto supomos. Freud considera esta segunda característica, que não se restringe aos sonhos, como notável e imprescindível ao acontecer psíquico. O que basicamente necessita ser demarcado é que o acontecer psíquico parte dos estímulos (internos e externos) e encaminha-se para a extremidade motora. 
Freud (1900/2007) volta a subdividir os traços mnêmicos conforme uma relação por simultaneidade, causalidade, e, em relação às representaçóes-palavra, ressaltando que nos primeiros sistemas mnêmicos $(M n)$ não existiria uma relação lógica entre os pensamentos, por isto se recorre à condição de figurabilidade. $\mathrm{O}$ sistema perceptivo oferece à consciência o que é da ordem da sensação, já os registros da memória seriam em si inconscientes. Contudo, mesmo quando os traços mnêmicos se tornam recordaçóes conscientes, não possuem a qualidade sensorial de uma percepção. Existe, como já foi dito, uma diferenciação no psiquismo entre percepção e representação. Desse modo, conforme Freud (1900/2007), nos sistemas psíquicos, memória e qualidade sensorial se excluem.

Freud questiona-se ainda sobre o caráter alucinatório dos sonhos, mais precisamente sobre a possibilidade de uma representação adquirir uma qualidade sensorial e confundir-se, assim, com uma percepção. $\mathrm{O}$ movimento que responde por este processo não mais seria o progressivo, visto que a excitação toma um caminho de refluxo (Rückläufig) e, desse modo, se dirige à percepção e não à motilidade. De tal sorte, o sonho possui uma qualidade intrínseca relacionada à regressão. É o movimento regressivo que responde pela postergação da ação - e não por sua cessação - e torna possível a reinscrição dos traços mnêmicos a partir da fantasia. Como bem nos mostra Freud (1907 [1906]/2007), a memória náo se perde no esquecimento, apenas descansa nele. Desse modo, a memória freudiana, assim como a ficção de Hitchcock, encontra-se em suspense.

A direção regressiva não se limita à formação do sonho, diz respeito, também, à recordação deliberada. Contudo, na vida de vigília este retorno não vai além das imagens mnêmicas, não produz, pois, a animação alucinatória que corresponde à percepção. Se o que diferencia o caráter alucinatório do sonho da recordação consciente é a possibilidade de uma imagem mnêmica transformar-se em imagem sensorial, o que produz esta peculiaridade no sonhar? Freud responde esta questão a partir de uma característica essencial do sistema mnêmico, qual seja: nos primeiros sistemas a lógica entre os pensamentos se dissipa. Desse modo, os sonhos alucinatórios não podem contar com a associação entre os pensamentos para se expressar, precisam se manifestar tal como as imagens perceptivas.

Este tipo de expressão destaca-se da lógica dos processos de pensamento. Mais precisamente, a identidade de percepção corresponde à colagem da representação com a coisa representada, não havendo, assim, um deslocamento que condicione o acontecer psíquico. É nesse sentido que uma imagem adquire o caráter alucinatório, no qual uma simples representação ganha valor de realidade que se impóe ao sujeito enquanto exterior a ele. 
Talvez neste sentido Freud (1900/2007, p. 613) tenha afirmado que "todo sonho tem um efeito despertante". Observação que o coloca diante de certas questóes quanto à temporalidade em curso nos sonhos: o processo de despertar requer um certo tempo e, durante o mesmo, o sonho ocorre. Freud é cuidadoso com relação a esta tese de E. Globot (1896, citado por Freud, 1900), embora se sinta atraído a considerá-la, ressaltando que o processo de elaboração onírica pode já ter começado durante o dia. O que se preserva nas entrelinhas deste raciocínio é que, mesmo no sonho, existe um momento de antecipação da consciência.

Pode-se pensar que também no suspense a construção da expectativa corresponde à construção desta consciência antecipativa. Em 1926 [1925, p. 189], Freud abre as suas "Observaçôes suplementares sobre a angústia" afirmando que "a angústia tem inegável relação com a expectativa: é a angústia por algo".

Desta maneira, o controle sobre o olhar do público, que acaba por construir também o filme, cria pelo menos uma relação de três termos: o diretor - através de sua câmera -, o filme e o público. Uma "trindade perpétua", como dizia Hitchcock. Se o cinema é para alguns uma máquina de fazer sonhos, com a pequena ovelhinha - assim como era chamado Hitchcock - a cortina foi rasgada, sonhos e realidade misturam-se.

\section{Referências}

Aumont, J. (1993). A imagem. Campinas: Parirus.

Bauso, T. M. (1991). Rope: Hitchcock's unkindest cut. Detroit: Wayne State University Press.

Bonitzer, P. (1982). L'écran du fantasme. Paris: Cahiers du cinéma.

Deleuze, G. (1990). A imagem-tempo. São Paulo: Brasiliense.

Freud, S. (2007). Proyecto de psicología. In S. Freud. Obras completas, v. I. Buenos Aires: Amorrortu Editores. (Trabalho original publicado em 1895).

Freud, S. (2007). Carta 52. In S. Freud. Obras completas, v. I. Buenos Aires: Amorrortu Editores. (Trabalho original publicado em 1896).

Freud, S. (2007). La interpretación de los sueños. In S. Freud. Obras completas, v. V. Buenos Aires: Amorrortu Editores. (Trabalho original publicado em 1900).

Freud, S. (2007). El delirio y los sueños en la Gradiva de W. Jensen. In S. Freud. Obras completas, v. IX. Buenos Aires: Amorrortu Editores. (Trabalho original publicado em 1907 [1906]).

Freud, S. (2007). La negación. In S. Freud. Obras completas, v. XIX. Buenos Aires: Amorrortu Editores. (Trabalho original publicado em 1925). 
Freud, S. (2007). Inhibición, síntoma y angustia. In S. Freud. Obras completas, v. XX. Buenos Aires: Amorrortu Editores. (Trabalho original publicado em 1926 [1925]).

Lacan, J. (1992). O seminário, livro 7: a ética da psicanálise. Rio de Janeiro: Jorge Zahar Editor (Seminário original de 1959-1960).

Quincey, T. (1993). O assassinato como uma das Belas Artes. Porto Alegre: LPM.

Sloan, J. E. (1993). Alfred Hitchcock: a guide to references and resourses. New York: G. K. Hall $\&$ Co.

Trías, E. (1986). Lo bello e lo sinistro. Barcelona: Seix Barral.

Truffaut, F. (1986). Hitchcock-Truffaut: entrevistas. São Paulo: Brasiliense. (Publicado originalmente em 1967).

Veillon, O. R. (1993). O cinema americano dos anos cinquenta. São Paulo: Martins Fontes.

Zizek, S. (2013). Menos que nada: Hegel e a sombra do materialismo dialético. São Paulo: Boitempo.

Recebido em 16 de setembro de 2012 Aceito para publicação em 26 de abril de 2013 